\title{
Role of cervical length assessment at mid-trimester scan for predicting preterm births: An experience from Tertiary Hospital
}

\section{Tamrakar SR', Shrestha $\mathbf{R}^{2}$}

'Suman Raj Tamrakar, Professor, Department of Obstetrics and Gynaecology, Kathmandu University School of Medical Sciences, Dhulikhel; ${ }^{2}$ Rubina Shrestha , Lecturer, Department of Obstetrics and Gynaecology, College of Medical Sciences, Bharatpur, Chitawan, Nepal.

\begin{abstract}
Background: Ultrasound has revolutionized the pattern of care and management. Mid trimester ultrasound (transabdominal) is a valuable method for pregnant clients to predict preterm births.

Objectives: To assess cervical length at 20 to 24 weeks obstetric scan for predicting risk of preterm delivery and to determine the sensitivity and specificity of assessing cervical length as a predictor of preterm delivery.

Methodology: This is a prospective study conducted at a Tertiary Hospital. Pregnant clients with singleton pregnancy at 20 to 24 weeks were enrolled for transabdominal ultrasound for assessing cervical length as a predictor of preterm delivery.

Results: Of 1027 pregnant clients screened, the mean age was $22.92 \pm 3.45$. Mean gestational age during scan was $21^{+5}$ weeks of gestation. About $2.43 \%$ of clients were found to have short cervix $<2.5 \mathrm{~cm}$ with mean cervical length $3.8 \mathrm{~cm}$. The risk of preterm delivery was almost two fold when cervical length was $<2.5 \mathrm{~cm}$. The sensitivity, specificity, positive predictive value and negative predictive value to predict preterm delivery were $32 \%, 85.9 \%, 5.44 \%$ and $98.04 \%$ respectively.

Conclusion: Assessment of the cervical length at mid-trimester can be useful tool for predicting risk of preterm delivery.

Key words: Cervical length; Mid trimester; Preterm birth; Transabdominal ultrasound
\end{abstract}

DOI: https://doi.org/10.3126/jkmc.v8i4.32383

\section{INTRODUCTION}

T.

Those births occurred before 37 completed weeks

of gestation is regarded as pre-term birth (PTB). Globally it is the leading cause of neonatal mortality and morbidity in terms of long-term disabilities, loss of life and health care cost. It complicates five to ten percent of all pregnancy. It is associated with 75 to $83 \%$ of perinatal mortality and morbidity ${ }^{1,2}$. A large proportion of these preterm births (37.6\%) occurred in South Asia, for a prevalence rate of $13.3 \%$ among all live births in the region $^{3}$. In Nepal, prevalence of PTB ranges from $6.9 \%$ to $14 \%{ }^{3-5}$.

Address for correspondence

\section{Dr. Suman Raj Tamrakar}

Kathmandu University of School Medical Sciences

E-mail: drsuman3947@gmail.com

ORCID id: https://orcid.org/0000-0002-4735-6851
The human cervix has been shown to be a dynamic organ throughout the gestation, varying markedly in both size and length. Different measures have been used to predict the risk of preterm labour (PTL) like anatomical measures (measurement of cervical length; $\mathrm{CL}$ ), physiological measure (monitoring of uterine contractions, cervical changes) and biochemical measures (level of foetal fibronectin in cervicovaginal secretion) with the variable result. Currently foetal fibronectin levels and ultrasound assessment of $\mathrm{CL}$ are comparatively promising ${ }^{6-9}$. And assessment of salivary oestradiol, phosphorylated insulin like growth factor binding protein-1 and cytokine are under investigation. Digital evaluation of the cervical changes has also been tried for its prediction but ultrasound measurement of the $\mathrm{CL}$ has been shown more effective and superior ${ }^{10}$.

Treatment of preterm babies is very expensive and unaffordable in developing countries. So, it is of great 
importance if we can prevent PTB. There are many Nepalese studies ${ }^{4,11-13}$ on different aspects of preterm labour (PTL) but no studies on prediction of preterm delivery by any means including ultrasound. Hence this study aimed to find the importance of ultrasound in measuring cervical length as a predictor of preterm delivery.

\section{METHODOLOGY}

This prospective study was conducted in the Department of Obstetrics and Gynaecology of a Tertiary Hospital from January 2015 to August 2016. This is a tertiary level hospital where more than 3500 deliveries take place annually. In this study, primigravida clients at 20 to 24 weeks were enrolled for transabdominal ultrasound for measuring cervical length. Exclusion criteria includes previous preterm delivery, preterm prelabour rupture of membranes (PPROM), multigravida, multifoetal gestation, placenta praevia, maternal obesity, maternal diabetes, polyhydramnious, uterine anomalies, history of domestic violence and history of cervical conization.

Altogether 3998 pregnant clients came for antenatal visit during the study period. Among them 1648 (41.2\%) were primigravida. Of them, 1242 met the inclusion criteria but 215 patients were lost during follow-up. So, 1027 primigravida clients were included in this study.

Cervical length is defined as the distance between the internal and external cervical os along the endocervical canal. The normal length of the cervix is distributed along a bell- shaped curve with a mean of $3.5 \mathrm{~cm}$ at 20 to 28 weeks of gestation. Many studies have used different technique to measure $\mathrm{CL}$; and transvaginal scan (TVS) was preferred to measure $C L$. The results of cervical length measured by transabdominal scan (TAS) could be shorter than that measured by TVS. But other sets of studies concluded that TAS could be used to assess $C L$ in low risk nulliparous clients. And the mean difference between these two technique was very minimal i.e. $0.29 \pm 0.15 \mathrm{~mm}$ in our set up. Hence TAS was used for measuring cervical length in this study.

After obtaining informed consent, TAS was undertaken by a single radiologist for all the participants undergoing cervical assessment. The shorter of the two measurements was recorded. Ethical clearance was taken from the hospital research committee (IRCKUSMS\#41/15). Data were entered in excel sheet and analyzed by SPSS 16 package using appropriate statistical tools like frequency, percentage, means, $p$ value, Chi square test.

\section{RESULTS}

In this prospective clinical study, 1027 pregnant clients were enrolled for cervix length assessment to find its relationship with gestational age at birth. The mean age was 22.92 \pm 3.45 (range 16 to 35 years). Most of the clients belonged to Janajati ethinicity $(n=536,52.2 \%)$. Of them, maximum clients $(n=263,25.6 \%)$ belonged to Newar community. None of the clients were smokers but two clients were social drinker.

Mean gestational age during scan was $21^{+5}$ weeks of gestation. About 25 (2.4\%) of the patients had cervical length $\leq 2.5 \mathrm{~cm}$. Funneling was seen in 16 cases. Of them, 12 had funneling as well as short cervical length.

Out of 1014 pregnant clients (after exclusion of 13 cases who were terminated for major congenital anomalies), eight pregnant clients with short cervix $(<2.5 \mathrm{~cm})$ delivered before 37 weeks.

In this study, when we took the $\mathrm{CL} \leq 2.5 \mathrm{~cm}$ as a short cervix, it had PPV of $5.44 \%$, NPV of $98.04 \%$, sensitivity is $32 \%$ and specificity is $85.9 \%$.

In this study, in pregnant clients with short cervix $(<2.5$ $\mathrm{cm}$ ), the RR of PTB was found 2.8 with $95 \%$ confidence interval (1.21-6.73). The risk of preterm delivery was almost two fold when $\mathrm{CL}$ was $<2.5 \mathrm{~cm}$.

Of 1014 cases, majority of pregnant clients 634 (62.5\%) delivered at term whereas 147 (14.5\%) had preterm delivery and 233 (23.0\%) had postdated delivery. Most of the pregnant clients $772(76.1 \%)$ had normal vaginal delivery, whereas 206 (20.3\%) underwent emergency caesarean section, $22(2.2 \%)$ underwent elective caesarean section and 14 (1.4\%) had vacuum delivery. Out of 147 preterm delivery, seven pregnant clients delivered before 28 weeks and 140 pregnant clients delivered at 29 to 36 weeks of gestation. Thirteen of them terminated between 20 to 24 weeks for having congenital anomalies in foetus.

Of 139 pregnant clients with cervical length $>2.5 \mathrm{~cm}$ who had preterm delivery, 110 (69.1\%) had some indications for it. Of them, 41 pregnant clients had PPROM, 16 had preeclampsia, eight had infection, seven each had intra uterine growth restriction, foetal distress, oligohydramnios, five had breech presentation, four had intra uterine foetal death and one had rheumatic heart disease. 
Table 1: Cervical length and gestational age $(n=1014)$

\begin{tabular}{ccccccc}
\hline Cervical Length & \multicolumn{2}{c}{ Gestational age in weeks at the time of delivery } & $\mathbf{4 0 +}$ & Total \\
$<2.5$ & $\mathbf{2 8}$ & $\mathbf{2 8 - 3 6}$ & $\mathbf{3 7 - 4 0}$ & 16 & 1 & 25 \\
$>2.5$ & $\mathbf{3}$ & 5 & 618 & 232 & 989 \\
\hline Total & 4 & 135 & 634 & 233 & 1014 \\
\hline
\end{tabular}

Table 2: Sensitivity, specificity, positive predictable value (PPV), negative predictable value (NPV) of cervical length $(<2.5 \mathrm{~cm})$ in relation to preterm birth $(<37$ weeks) $(n=1014)$

\section{Diagnostic Statistics}

True positive ( $\mathrm{CL} \leq 2.5 \mathrm{~cm}$, had preterm delivery) 8

False positive $(\mathrm{CL} \geq 2.5 \mathrm{~cm}$, had preterm delivery) 139

False negative $(\mathrm{CL} \leq 2.5 \mathrm{~cm}$, but delivered at term)

17

True negative ( $C L \geq 2.5 \mathrm{~cm}$, but delivered at term) 850

Sensitivity \% $32 \%$

Specificity \% $85.9 \%$

PPV \%

$5.44 \%$

NPV\% $98.04 \%$

Table 3: Odds ratio (OR) of preterm delivery in cervical length $<\mathbf{2 . 5} \mathbf{c m}$

\begin{tabular}{|c|c|c|c|c|}
\hline \multirow{2}{*}{ Cervical Length } & \multicolumn{3}{|c|}{ Gestational age at the time of delivery } & \multirow{2}{*}{ P value } \\
\hline & Preterm $(n=147)$ & Term $(n=867)$ & Total & \\
\hline$\leq 2.5 \mathrm{~cm}$ & $8(32 \%)$ & $17(68 \%)$ & $25(100 \%)$ & \multirow{2}{*}{$<0.01$} \\
\hline$>2.5 \mathrm{~cm}$ & $139(14.1 \%)$ & $850(85.9 \%)$ & $989(100 \%)$ & \\
\hline Odds Ratio (OR) & \multicolumn{4}{|c|}{1.96} \\
\hline
\end{tabular}

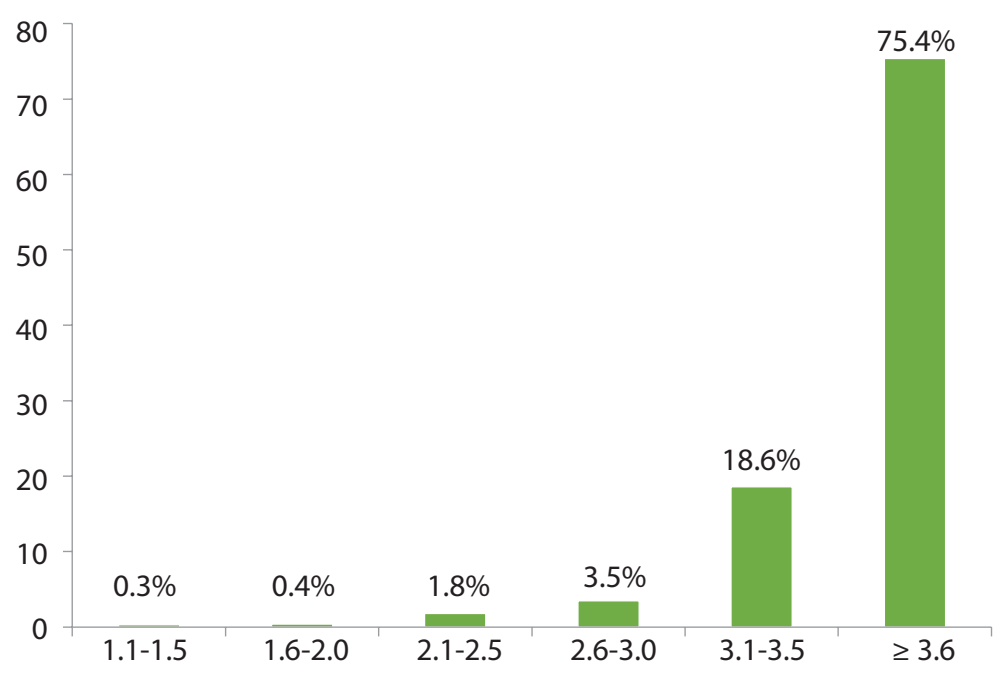

Figure 1: Distribution of cervical length assessment $(\mathrm{cm})(\mathrm{n}=1014)$ 


\section{DISCUSSION}

Every pregnant woman desires to have a mature baby. Preterm birth is the major clinical problem and a challenge for obstetrician to predict and prevent PTB $^{14}$.

Age range of the mothers who had PTB was 20 to 28 years and 17 to 44 years in studies by $\mathrm{KC}$ et al and Ojha $\mathrm{N}$ respectively ${ }^{4,5}$. In this study, the mean age was 22.92 \pm 3.45 (range 16 to 35 years).

In a study by Ojha N, about two thirds of study subjects were Indo-Aryans ethnicity and one third were TibetoBurmans ethnicity ${ }^{4}$. KC et al. found almost half $(45.5 \%$ to $47.1 \%$ ) of study subjects were Jananatis ethnicity ${ }^{5}$. In this study, most of the clients belong to Janajati ethinicity $(n=536,52.2 \%)$ and among Janajati, Newar $(n=263$, $25.6 \%$ ) were maximum.

Cervical length in the general obstetrical population is relatively constant in pregnancy until third trimester. But in women who deliver preterm the rate of cervical shortening is faster than in women who deliver at term. In a woman who goes into PTL or preterm delivery the range of $C L$ decline varies from 0.5 to $8 \mathrm{~mm}$ per week ${ }^{15}$. In this study, mean gestational age during scan was $21^{+5}$ weeks of gestation. And the mean $C L$ was $3.8 \mathrm{~cm}$. In a study by Heath VC et al. ${ }^{16}$, they found a mean $\mathrm{CL}$ of 3.8 $\mathrm{cm}$ at 23 weeks. lams JD et al. ${ }^{17}$ found a mean $\mathrm{CL}$ of 3.5 $\mathrm{cm}$ at 24 weeks and of $3.4 \mathrm{~cm}$ at 28 weeks and Kore SJ et al. ${ }^{18}$ showed a mean $C L$ of $3.64 \pm 0.8 \mathrm{~cm}$.

There is a lack of agreement in the description of funneling as a predictor for the risk of PTB. Even though funneling is best measured as categoric variable, it should be reported as present or absent. In a woman with an atypical history of cervical incompetence (uterine cramps, abdominal pressure, bloody show or a watery discharge), criteria for diagnosis include $C L$ less than fifth or tenth percentile $(2 \mathrm{~cm}$ to $2.5 \mathrm{~cm})$ and funneling greater than $30 \%$ of total length of cervix ${ }^{19}$.

Rust OA et al. ${ }^{20}$ compared the obstetrical outcome of 82 women with a T- shaped cervix and no funnel and 82 patients matched with a typical $Y$ shaped funnel. The funnel group had significantly more readmission for preterm labor, chorioamnionitis, abruption, PPROM, and cerclage placement. The presence of funneling significantly increases the risk for adverse perinatal outcome. In this study, funneling was seen in 16 (1.6\%) cases. Of them, 12 had funneling as well as short $\mathrm{CL}$. Increased risk of pre-term birth has been associated with short cervix and effacement. Cervical length assessment at mid pregnancy may predict preterm delivery as shortening of cervix occurs about 10 weeks before onset of labour ${ }^{21,22}$. So ultrasonological assessment of the $C L$ in second trimester may facilitate the diagnosis and management of the incompetent cervix and PTL.

A $2.5 \mathrm{~cm}$ cut-off of $\mathrm{CL}$ identifies those clients truly at high risk for preterm delivery. The preliminary results of the Cervical Incompetence Prevention Randomized Cerclage Trail (CIP- RACT) ${ }^{23}$ showed that $62.5 \%$ of the clients with a $\mathrm{CL}<2.5 \mathrm{~cm}$ delivered before 34 weeks of gestation. In this study, cut off value for short $C L$ was taken as $\leq 2.5 \mathrm{~cm}$ as in other studies ${ }^{17,24-26}$.

Cervical length is inversely related to the risk of PTB in asymptomatic women. The risk of PTB is inversely proportional to $\mathrm{CL}$ of $<2.5 \mathrm{~cm},<2.0 \mathrm{~cm}$ and $<1.5 \mathrm{~cm}$ had $18 \%, 25 \%$ risk and $50 \%$ risk of PTB respectively ${ }^{27}$. Heath VC et al. ${ }^{16}$ reported that a $\mathrm{CL}<1.5 \mathrm{~cm}$ at 23 gestational week is inversely correlated with delivery before 33 weeks. In $58 \%$ of women who had an early preterm delivery, the $C L$ was $<1.5 \mathrm{~cm}$.

According to Moroz LA and Simhan $\mathrm{HN}^{28} \mathrm{CL}<2.5 \mathrm{~cm}$ is associated with PTB, and every one $\mathrm{mm}$ shortening of the cervix on sonography indicates a 3\% increase in the odds of PTB. lams JD et al. ${ }^{17}$ compared CL in a woman with high risk of PTB with normal woman at 24 weeks and found that $\mathrm{CL}$ less than $3.0,2.6,2.2 \mathrm{~cm} 1.3$ had the increased risk of PTB by four, six, nine and fourteen times. But the PPVs (6 to $44 \%$ ) and sensitivity $47 \%$ were poor in the low risk population. In the study done by Anderson et al. ${ }^{29}$ the estimated risk of preterm delivery increases exponentially with decreasing $\mathrm{CL}$ from 0.2 $\%$ at $6.0 \mathrm{~cm}$ to $0.8 \%$ at $3.0 \mathrm{~cm}, 4 \%$ at $1.5 \mathrm{~cm}$ and $78 \%$ at $0.5 \mathrm{~cm}$. Though low positive predictive value limits the usefulness of cervical length measurement, the high negative predictive value as in our study helps in choosing appropriate interventions and can be used in screening of low risk pregnant clients.

Since the risk of preterm birth increases markedly when cervix is $<2.5 \mathrm{~cm}$, this measurement has been widely accepted as the threshold to predict the risk of preterm birth. The PPV that the women with short cervix $<2.5 \mathrm{~cm}$ will have preterm delivery is $17.8 \%$, which is higher than a normal risk. The NPV that the women with $\mathrm{CL}>2.5 \mathrm{~cm}$ will deliver at term is $97 \%{ }^{30}$. Taipale $\mathrm{P}$ et al. ${ }^{31}$ measured $\mathrm{CL}(\mathrm{n}=3694)$ with cut off for $\mathrm{CL}<3.0 \mathrm{~cm}$ at 18 to 22 weeks and clients who delivered before 35 weeks had sensitivity of $19 \%$, specificity of $91 \%$ and PPV of $1.8 \%$. Goldenberg RL et al. ${ }^{32}$ used $C L$ of $2.5 \mathrm{~cm}$ as a short cervix between 24 to 30 weeks of gestation, positive fetal fibronectin was the strongest predictor of PTB followed by short CL. 
Short $\mathrm{CL}$ however, even when combined with positive fetal fibronectin had a low PPV for PTB (18\%) in clients with low risk. In this study, when we took the $\mathrm{CL} \leq 2.5$ $\mathrm{cm}$ as a short cervix, it had PPV of 5.44\%, NPV of $98.04 \%$, sensitivity is $32 \%$ and specificity is $85.9 \%$. And the RR of preterm delivery is 2.8 ( $95 \%$ confidence interval, 1.21 to 6.73), which is comparable to study done by lams et al. found RR of 3.79 (95\% confidence interval, 2.32 to 6.19 ) when $\leq \mathrm{CL} 3.0 \mathrm{~cm}^{17}$.

We do agree that TVS is superior to TAS for the cervical length assessment, which is accepted by the international bodies like the Royal College of Obstetricians and Gynaecologists (RCOG) and American College of
Obstetricians and Gynecologists (ACOG). However, the limitations in our settings resulted into taking up of TAS method for the cervical length assessment.

\section{CONCLUSION}

Measurement of the cervical length at mid-trimester can be useful tool for predicting risk of preterm delivery. Cervical length is inversely related to the risk of PTB in these clients. Cervical length of more than $2.5 \mathrm{~cm}$ has a high specificity for not having a preterm delivery. Further randomized studies are required to confirm and prove effectiveness of interventions in preventing PTB in clients with $\mathrm{CL}<2.5 \mathrm{~cm}$.

\section{REFERENCES}

1. Goldenberg RL, Culhane JF, lams JD, Romero R. Epidemiology and causes of preterm birth. Lancet 2008; 371(9606):75-84. [DOI]

2. Goswami K, Thornton S. Progress in Obstetrics and Gynaecology. Vol. 17. New Delhi: John Studd, Edinburg, Churchill Livingstone; 2006. The prevention and treatment of preterm labor. [Google Scholar]

3. Lee $A C$, Katz J, Blencowe $H$, Cousens S, Kozuki N, Vogel JP, et al. National and regional estimates of term and preterm babies born small for gestational age in 138 low-income and middle-income countries in 2010. Lancet Glob Health. 2013;1(1):e26-36. [DOI]

4. Ojha N. Maternal factors for low birth weight and preterm birth at tertiary care hospital. J Nepal Med Assoc 2015;53(200):250-5. [DOI]

5. KC A, Wrammert J, Nelin V, Ewald U, Clark R, Målqvist M. Level of mortality risk for babies born preterm or with a small weight for gestation in a tertiary hospital of Nepal. BMC Public Health (2015) 15:877. [DOI]

6. lams JD. Prediction and early detection of preterm labor. ObstetGynecol 2003; 101(2):402-12.[DOI]

7. Fonseca EB, Celik E, Parra M, Singh M, Nicolaides $\mathrm{KH}$. Fetal Medicine Foundation Second Trimester Screening Group. Progesterone and the risk of preterm birth among women with a short cervix. N Engl J Med 2007; 357(5):462-9. [FULLTEXT]

8. Hassan SS, Romero R, Vidyadhari D, Fusey S, Baxter JK, Khandelwal $M$, et al. Vaginal progesterone reduces the rate of preterm birth in women with a sonographic short cervix: a multicenter, randomized, double-blind, placebo-controlled trial. Ultrasound ObstetGynecol 2011; 38(1):18-31.[DOI]

9. To MS, Alfirevic Z, Heath VC, Cicero S, Cacho AM, Williamson PR, et al. Cervical cerclage for prevention

of preterm delivery in women with short cervix: randomised controlled trial. Lancet 2004 Jun; 363(9424):1849-53.[DOI]

10. Andersen HF, Nugent CE, Wanty SD, Hayashi $\mathrm{RH}$. Prediction of risk for preterm delivery by ultrasonographic measurement of cervical length. Am J ObstetGynecol 1990; 163(3):859-67. [DOI]

11. Shrestha L, Shrestha P. Mortality and morbidity pattern of preterm babies at Tribhuvan University Teaching Hospital. J Nepal Paediatr Soc 2013;33(3):201-5. [DOI]

12. Poudyal $P$, Joshi $A$, Bastakoti $R, K C D$, Shrestha RPB, Shrestha PS. Risk factors and clinical profile of preterm deliveries at Dhulikhel Hospital, Kathmandu University Hospital. Kathmandu Univ Med J. 2018;63(3):248-52. [DOI]

13. Paudel L, Kalakheti B, Sharma K. Prevalence and outcome of preterm neonates admitted to neonatal unit of a tertiary care center in Western Nepal. Journal of Lumbini Medical College. 2018;6(2):6 pages. Epub: 2018 Dec 8.[DOI]

14. Goffinet F. Primary predictors of preterm labour. BJOG 2005; 112:38-47. [DOI]

15. Naim A, Haberman S, Burgess $T$, Navizedeh $N$, Minkoff $\mathrm{H}$. Changes in cervical length and the risk of preterm labor. Am J Obstet Gynecol. 2002; 186(5):887-9. [DOI]

16. Heath VC, Southall TR, Souka AP, Elisseou A, Nicolaides $\mathrm{KH}$. Cervical length at 23 weeks of gestation: prediction of spontaneous preterm delivery. Ultrasound ObstetGynecol 1998;12:312-7. [DOI]

17. lams JD, Goldenberg RL, Meis PJ, Mercer BM, Moawad A, Das A, et al. The length of the cervix and the risk of spontaneous premature delivery. $\mathrm{N}$ Engl J Med 1996 Feb; 334(9): 567-72. [DOI] 
18. Kore SJ, Parikh MP, Lakhotia S, Kulkarni V, Ambiye VR. Prediction of risk of preterm delivery by cervical assessment by trans vaginal ultrasonography. J ObstetGynecol India 2009; 59:131-5. [FULLTEXT]

19. Berghella V, Tolosa JE, Kuhlman K, Weiner S, Bolognese RJ, Wapner RJ. Cervical ultrasonography compared with manual exam as a predictor of preterm delivery. Am J ObsGynecol 1997; 177(4):723-30. [DOI]

20. Rust OA, Atlas RO, Kimmel S, Roberts WE, Hess LW. Does the presence of a funnel increase the risk of adverse perinatal outcome in a patient with a short cervix? Am J ObstetGynecol 2005;192(4):1060-6. [DOI]

21. Bloom SL, Yost NP, McIntire DD, Leveno KJ. Recurrence of preterm birth in singleton and twin pregnancies. ObstetGynecol 2001 Sep;98(3):379-85. [DOI]

22. Arbyn M, Raifu AO, Koliopoulos G, Martin-Hirsch P, Prendiville W, Paraskevaidis E, et al. Perinatal mortality and other severe adverse pregnancy outcomes associated with treatment of cervical intraepithelial neoplasia: metaanalysis. BMJ 2008; 337:a1284. [DOI]

23. Althiusius SM, Dekker GA, van Geijn HP, Bekedam DJ, Hummel P. Cervical Incompetence Prevention Randomized Cerclage Trail (CIPRACT): study design and preliminary results. Am J ObstetGynecol 2000; 183(4):823-9. [DOI]

24. Owen J, Yost N, Berghella V, Thom E, Swain M, Dildy $\mathrm{GA}$, et al. Mid-trimester endovaginal sonography in women at high risk for spontaneous preterm birth. JAMA. 2001;286:1340-8.[DOI]

25. Hebbar S, Samjhana K. Role of mid-trimester transvaginal cervical ultrasound in prediction of preterm delivery. Med J Malaysia. 2006;61(3):30711.[DOI]

26. Priyadarshani $P$, Kaur G. Predicting preterm labour by cervical length measurement. Int J Reprod Contracept ObstetGynecol 2016;5:1809-13. [DOI]

27. Honest H, Bachmann LM, Coomarasamy A, Gupta JK, Kleijnen J, Khan KS. Accuracy of cervical transvaginal sonography in predicting preterm birth: a systemic review. Ultrasound ObstetGynaecol 2003;22(3):30522.[DOI]

28. Moroz LA, Simhan HN. Rate of sonographic cervical shortening and the risk of spontaneous preterm birth. Am J ObstetGynecol 2012; 206(3):234.e1-234. e5. [DOI]

29. Andersen HF. Transvaginal and transabdominal ultrasonography of the uterine cervix during pregnancy. J Clin Ultrasound 1991; 19(2):7783. [DOI]

30. Friedman AM, Srinivas SK, Parry S, Elovitz MA, Wang E, Schwartz N. Can transabdominal ultrasound be used as a screening test for short cervical length? Am J ObstetGynecol 2013; 208(3):190.e1-190e7. [DOI]

31. Taipale $P$, Hiilesmaa V. Sonographic measurement of uterine cervix at 18-22 weeks gestation and the risk of preterm delivery. ObstetGynaecol 1998; 92(6):902-7. [DOI]

32. Goldenberg RL, lams JD, Das A, Mercer BM, Meis PJ, Moawad $\mathrm{AH}$, et al. The Preterm Prediction Study: sequential cervical length and fetal fibronectin testing for the prediction of spontaneous preterm birth. National Institute of Child Health and Human Development Maternal Fetal Medicine Units Network. Am J ObstetGynecol 2000; 182:636-43. [DOI] 